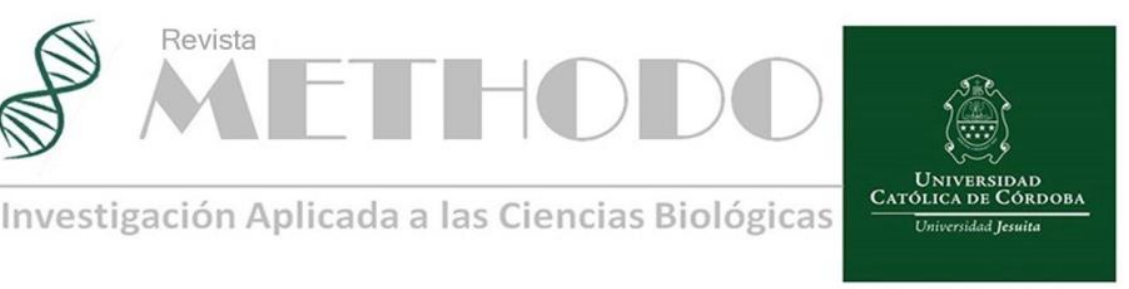

EDITORIAL Rev. Methodo 2021;6(3):111-112 https://doi.org/10.22529/me.2021.6(3)01 Solicitado. 30 Mar. 2021| Recibido. 17 Jun. 2021 | Publicado. 02 Jul. 2021

\title{
La escritura en la universidad
}

\section{Writing in the university}

Escribir en la universidad es una tarea compleja, incluso para quienes, dedicados a la investigación, se valen de la escritura en tanto actividad de generación de conocimiento y desarrollo del pensamiento propio. De allí que las dificultades de la escritura van más allá de cuestiones relacionadas con la ortografía, la gramática, el estilo de citación. En el ecosistema universitario, a través de la escritura, tanto estudiantes, docentes como investigadores e investigadoras aprenden un modo de ver y representar el mundo, ya que cada instancia de la que participan está conformada no solo por un conjunto de conceptos propios de la disciplina sino también por modos específicos de pensar que están vinculados a formas particulares de escribir ${ }^{1}$.

Los modos de leer y escribir, es decir de adquirir, elaborar y comunicar conocimiento, varían no solo según la disciplina sino también según el contexto. Así, el proceso de aprendizaje de la escritura académica y científica se extiende incluso más allá de la finalización de los estudios, en la medida en que cada nuevo evento del que se participe exige responder de un modo adecuado y eficaz, según el tema, la tipología textual, el propósito de escritura y la comunidad a quien se destina el texto -a veces más amplia, como ocurre con los textos de divulgación científica; a veces mucho más restringida, tal el caso de los artículos de investigación científica-.

En el texto, el sujeto de la enunciación -el autor, la autora- plasma, a su vez, una imagen de sí que responde a las exigencias del discurso académico; se muestra, frente a esa comunidad lectora, como alguien que sabe del tema, que ha rastreado con rigurosidad sus antecedentes, que expone las ideas con pensamiento crítico y originalidad. Esta imagen recibe el nombre de ethos discursivo. Cuanto más consciente es el autor, la autora de que cada vez que enfrenta el desafío de escribir un texto construye en él una imagen de sí mismo, de sí misma mayor eficacia tiene la escritura, en tanto el ethos se relaciona directamente con la credibilidad que se logra mediante el ejercicio de la palabra. "Lo que el autor del discurso quiere ser lo deja entender y ver: no dice que es simple y honesto, sino que lo muestra por medio de su manera de expresarse"2.

Revista Methodo: Investigación Aplicada a las Ciencias Biológicas. Facultad de Medicina. Universidad Católica de Córdoba. Jacinto Ríos 571 Bo Gral. Paz. X5004FXS. Córdoba. Argentina. Tel.: (54) 3514517299 / Correo: methodo@ucc.edu.ar / Web: methodo.ucc.edu.ar | EDITORIAL Rev. Methodo 2021;6(3):111-112. 
Frente a este enorme desafío, la tarea de quienes acompañamos el ejercicio de la escritura en la universidad debe disponerse desde un sentido que se aleja de lo punitivo, que castiga cuando el autor, la autora no logra hacer de su texto un ejercicio de claridad, adecuación y honestidad; y se acerca al rol de custodio de estos principios básicos y a partir de allí de facilitador, para que quienes escriben en la universidad puedan gradualmente ser reconocidos, reconocidas en el campo disciplinar al que desean pertenecer.

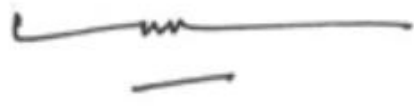

Carla Slek

Directora Editorial (EDUCC)

Universidad Católica de Córdoba

Bibliografía

1- Bazerman, C. (2014). El descubrimiento de la escritura académica. En F. Navarro (Ed.), Manual de escritura para carreras de humanidades (pp. 11-16). Buenos Aires: Editorial de la Facultad de Filosofía y Letras Universidad de Buenos Aires.

2- García Negroni, M. M. y Ramírez Gelbes, S. (2005). Polémica y agente. El caso de sin embargo y no obstante en los abstracts académicos. En Actas del Congreso Internacional de Letras: Debates actuales. Las teorías críticas de la literatura y la lingüística. Buenos Aires, Facultad de Filosofía y Letras de la Universidad de Buenos Aires.

\section{(c) (1) \&(0

